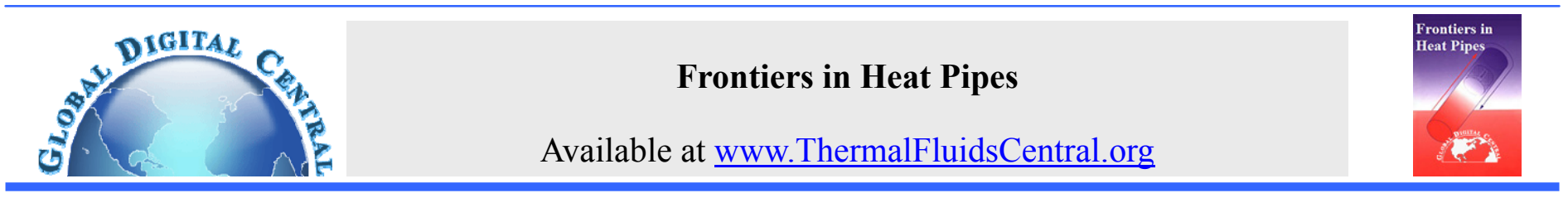

\title{
AN EXPERIMENTAL INVESTIGATION OF THE THICKNESS OF THE LIQUID-FILM DEPOSITED AT THE TRAILING END OF A LIQUID PLUG MOVING IN THE CAPILLARY TUBE OF A PULSATING HEAT PIPE
}

\author{
RT Dobson, ${ }^{\mathrm{a}, *}, \mathrm{G}$ Swanepoel ${ }^{\mathrm{b}}$ \\ ${ }^{a}$ Department of Mechanical Engineering, University of Stellenbosch, Stellenbosch, 7602, South Africa \\ ${ }^{b}$ Westinghouse South Africa, Swartkop, 1747, South Africa
}

\begin{abstract}
For the theoretical modelling of pulsating heat pipes it is necessary to estimate the thickness of the liquid film deposited at the trailing edge of a liquid plug as it moves through a small diameter tube. A simple experimental set-up and procedure whereby this liquid film thickness may be determined is described and a correlation for the thickness is statistically derived. Using water as the working fluid at temperatures between 0 and 60 ${ }^{\circ} \mathrm{C}$ and velocities of 0.3 to $1.8 \mathrm{~m} / \mathrm{s}$ the average film thickness varied between 100 and $200 \mu \mathrm{m}$ and depended primarily on the surface tension of the liquid.
\end{abstract}

Keywords: Pulsating heat pipe, liquid film thickness, experimental correlation, oscillatory heat pipe.

\section{INTRODUCTION}

A pulsating (or oscillatory or oscillating) heat pipe (PHP) is a heat transfer device invented some twenty years ago (Akarchi, 1990 and 1993) and by 1995 had already been intensively researched and many application areas considered. In particular its potential in the cooling of electronic equipment had been emphasized (Akarchi and Polášek, 1996). A PHP consists of a relative long sealed capillary tube that has been wound back and forth in one plane; reminiscent of a river as it meanders along in a relatively horizontal plain. It is evacuated and then charged with a working fluid (for example water, ammonia, methanol or Freon) at a liquid fill ratio (liquid to total volume) of $50 \%$. The liquid in the pipe then tends to naturally distributed itself into many ostensibly randomly spaced and sized liquid-slugs and vapour-bubbles as shown in Fig. 1, provided that the pipe diameter is in the order of 0.5 to 1.8 of the so-called capillary length $L$, as given by:

$L=\sqrt{\frac{\sigma}{\left(\rho_{\ell}-\rho_{v}\right) \mathrm{g}}}$

If the diameter is too large, the liquid will tends to stratify into a single liquid layer and a vapour layer, and if the diameter is too small then the intensity of the relative movement between the liquid and vapour may be inhibited due to capillarity.

If the one end of the PHP is heated and the other end cooled (see Fig. 1) heat is transferred from the heat source to the cooler heat sink.

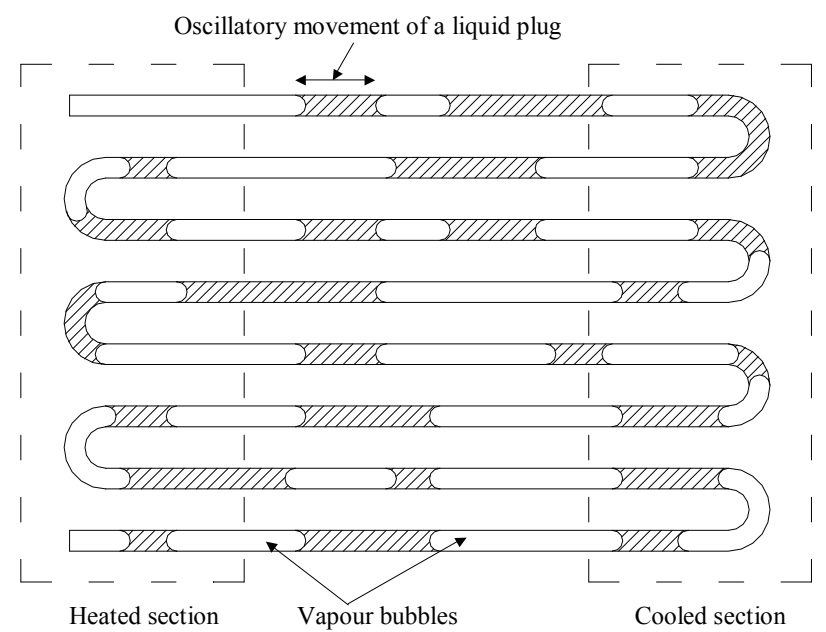

Fig. 1 A pulsating heat pipe consisting of liquid plugs and vapour bubbles in a small-diameter pipe.

This is seen to always spontaneously occur in the so-called bottom heat mode (that is when the heated end is below the cooled end) even at low $\left(<40{ }^{\circ} \mathrm{C}\right)$ temperature differences. The liquid plug vapour bubble behaviour in this heat mode is characterised (as observed in glass PHPs) by a seemingly sudden and chaotic burst of rapid motion of the plugs and bubbles, back and forth, and around the bends, followed by a relatively quiescent dwell period. This rapid motion followed by

\footnotetext{
${ }^{*}$ Corresponding author: Email:rtd@sun.ac.za
} 


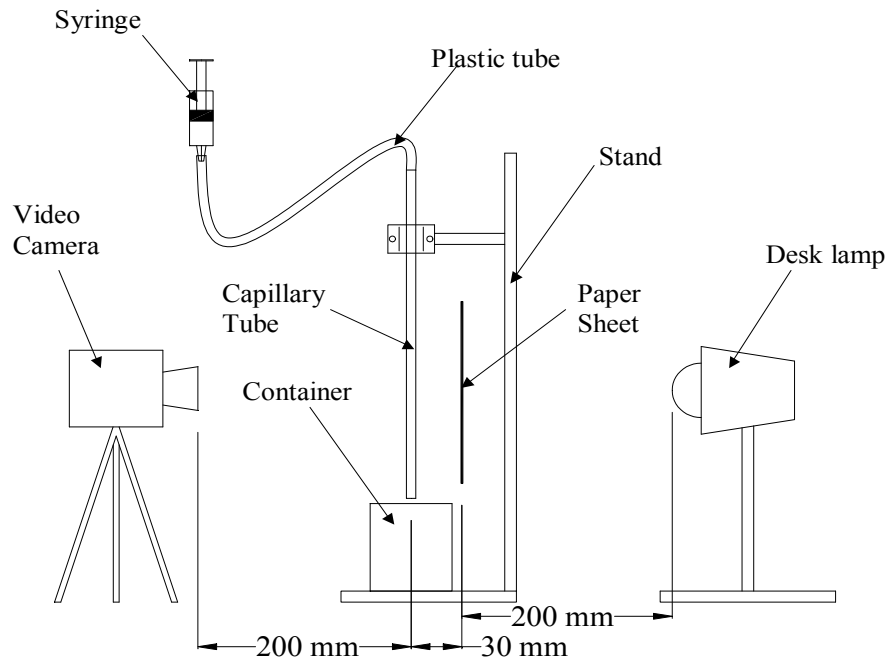

Fig. 2 Experimental set-up.

quiescent periods continues for as long as there is a temperature difference between the heated and cooled ends, hence the name pulsing heat pipe, and heat continues to be transferred. This is what may be called a low heat flux operating condition. If the heated section is above the cooled end (called the top heat mode) heat pipe will start to transfer heat, and against gravity, when the temperature difference exceeds about $60{ }^{\circ} \mathrm{C}$ (Dobson and Graf, 2003). This can be called the high heat flux operating condition and the flow behaviour in this mode may be characterised by a uni-directional annular type of flow reminiscent of the annular convective two-phase flow and heat transfer flow pattern regime (Carey, 1992).

The relatively simple liquid plug-vapour bubble geometry in low heat flux mode lends itself to theoretical analysis and mathematical formulation by applying the equations of change; that is the conservation of mass, momentum and energy, to the relatively discrete liquid and vapour control volumes, and using the constituent working fluid property equations for closure. Wong, et al. (1999) proposed a simple liquid plug and vapour bubble theoretical model. Dobson and Harms (1999) however included a film thickness in their simply liquid plug and vapour bubble model and showed that the model tended to capture the oscillatory behaviour of PHPs. This theoretical approach was also applied to a single vapour bubble-two-liquid plug open oscillatory heat pipe and it was able to successfully capture the chaotic behaviour that is observed in to occur in this type of PHP (Dobson, 2002 and 2003). Other papers by Zhang and Faghri, 2002; Shafii, Faghri and Zhang (2003); Khandekar and Groll (2008); Shao and Zhang (2010) have also presented theoretical models, and others (Charoensawan, et al.) have experimentally explored the detailed behaviour of PHPs. Tripath, Khandekar and Panigrahi (2010) consider the liquid-vapour-solid contact region. Only one other paper (Senjaya, Inoue and Suzuki, 2010) pertinently considers the liquid film thickness. In this paper no mention is made of what the thickness of the liquid left behind by the trailing edge of the liquid plug might be but assumes however that the film thickness is the same in both the evaporating and condensing sections.

If the PHP is charged with a $50 \%$ fill ratio of working fluid then, correspondingly, about $50 \%$ of the inside pipe surface area is in contact with liquid plugs the rest of the inside surface is in contact with vapour bubbles. Once the PHP starts working the moving liquid plugs leave behind at their trailing ends a thin layer of fluid of finite thickness on the pipe surface and at the leading front take up liquid left behind by the preceding liquid plugs. At any one time thus $50 \%$ of the heat transfer, ignoring any axial heat transfer, is associated with liquid plugs. For the remaining surface the heat transfer will then be associated with a relatively intact liquid film; increasing in thickness in the condensing sections and decreasing in thickness in the evaporating sections.

For the theoretical modelling of pulsating heat pipes an idea of the thickness of the liquid film deposited at the trailing edge as it moves through a capillary tube is thus needed. It is the object of this paper to present a simple experimental procedure whereby this liquid layer may be estimated for water. The experimental set-up and procedure is given and the observed liquid behaviour is described. The results are statistically analysed and a correlation for the liquid thickness is presented and conclusions are drawn.

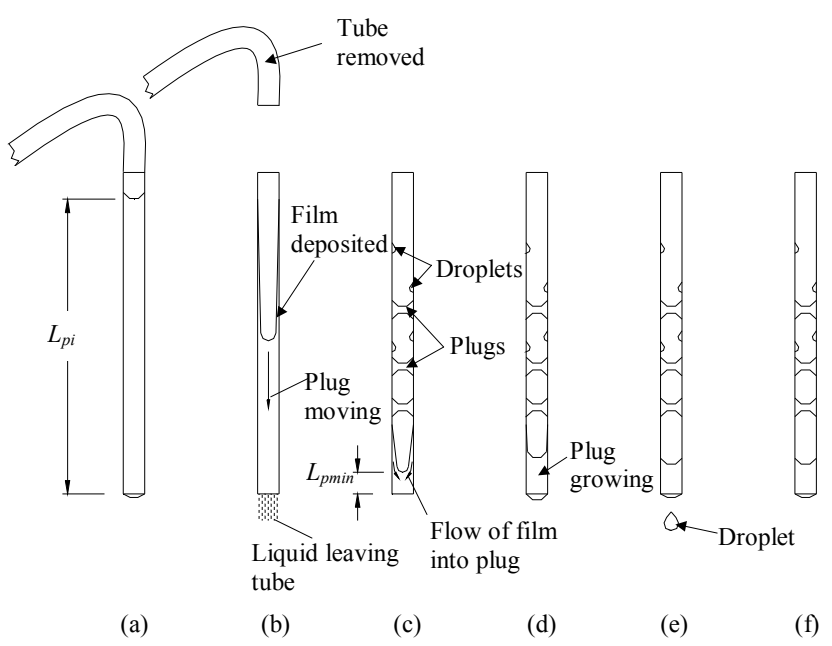

Fig. 3 Experimentally observed behaviour a liquid plug moving in a capillary tube.

\section{EXPERIMENTAL SET-UP}

A simple experimental set-up was devised to determine the average thickness of the liquid film deposited by the trailing-end of a liquid plug as it moves along in a small diameter pipe. The experimental setup consists of a vertically orientated capillary tube clamped to a retort stand as shown in Fig. 2. The top end the capillary tube is connected to a syringe using a short length of plastic tubing. A video camera (JVC GV-DS1) is positioned as shown and is used to capture the movement of the liquid. A desk lamp is positioned behind a sheet of paper to attain the required lighting.

Before clamping the capillary tube to the stand the dry mass of the tube is measured (using a Precisa 40SM-200A, serial no. 73464 scale). The liquid to be tested is heated to the desired temperature and then positioned in a container at the bottom end of the capillary tube so that the end portion of the capillary tube is submerged in the liquid. The syringe is then used to draw the liquid up into the capillary tube until the desired level of the liquid is obtained. (The higher the liquid is drawn up into the tube the faster the average velocity of the liquid as it flows downwards under the influence of gravity.) The container is then lowered to allow the liquid to move freely out of the lower end of the capillary tube. The plastic tubing is quickly disconnected from the capillary tube and the liquid plug starts to move down the capillary tube due to gravity. This movement of the liquid plug is captured by the video camera.

\section{OBSERVATIONS}

The initial length of the liquid column $L_{p i}$ drawn into the capillary tube by the syringe is shown in Fig. 3(a). After the plastic tube is disconnected the liquid plug starts to move down and a liquid film is deposited at the trailing end as shown in Fig. 3(b). A portion of the 
liquid plug of a length $L_{p, \min }$ will remain in the tube depending on the magnitude of the momentum of the liquid plug, the friction and the surface tension as shown in Fig. 3(c). As the liquid film flows down the tube the remaining plug of liquid increases from $L_{p, \min }$ to say $L_{p f i n a l}$. As the thickness of the liquid film decreases the uniform film breaks up into several droplets along the inside, also several small liquid plugs are formed along the tube. Some of the liquid film flows into the portion of the liquid plug at the exit as shown in Fig. 3(c). The flow of the liquid film into the liquid plug will cause it to grow as shown Fig. 3(d). Only a limited mass of liquid in the plug can be supported by the capillary forces against gravity, and a few liquid droplets may break away from the bottom as shown in Fig. 3(e). After a while equilibrium is achieved as shown in Fig. 3(f).

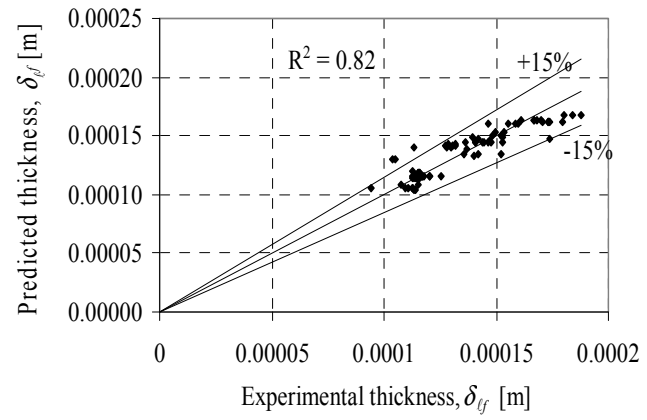

Fig. 4 Predicted film thickness, using Eq. (7), as a function of the experimentally determined values.

\section{ANALYSIS AND RESULTS}

The average film thickness of the liquid deposited by the trailing end of the liquid plug $\delta_{\ell f}$ is given by the following equation

$\delta_{\ell f}=\frac{d_{i}}{2}-\frac{1}{2} \sqrt{d_{i}^{2}-\frac{4 m_{\ell f}}{\pi\left(L_{p i}-L_{p \min }\right) \rho_{\ell}}}$

where $d_{i}$ is the inside diameter of the capillary tube, $L_{p i}$ is the initial length (height) of the liquid column, and $L_{p \min }$ is the minimum instantaneous height of the liquid column at the instant just as the trailing liquid starts to replenish the minimum amount of liquid remaining in the tube. $\rho_{\ell}$ is the density of the liquid, $m_{\ell f}$ is the total mass of the liquid film deposited on the surface of the tube and may be determined using Eq. (3) as

$m_{\ell f}=m_{t \ell}-m_{t d}-\frac{1}{4} \pi d_{i}^{2} \rho_{\ell} L_{p \min }+m_{d r o p s}$

where, $m_{t \ell}$ is the mass of the tube partially filled with liquid, $m_{t d}$ is the dry mass of the tube, $\frac{1}{4} \pi d_{i}^{2} \rho_{\ell} L_{p \text { min }}$ is the the mass of the liquid plug left in the tube due to surface tension, and $m_{\text {drops }}$ is the mass of the any liquid drops that may have fallen from the remaining liquid as its height increases due to it being replenished by the liquid film.

The average velocity of the trailing end of the liquid plug as it falls in the tube is determined using Eq. (4)

$v_{p}=\frac{L_{p i}-L_{p \min }}{\Delta t}$
It is not unreasonable to assume that the variables primarily affecting the thickness of the liquid film might include the inside diameter of the capillary tube $d_{i}$, the surface tension $\sigma$ and viscosity $\mu$ of the liquid water, and the average velocity of the trailing end of the liquid plug $v_{p}$. The effect of each of these variables may be evaluated using statistical analysis by assuming a power function relationship, as is often done in determining semi-empirical equations for heat transfer coefficients (Mills, 1999), as

$\delta_{\ell f}=a_{0} d_{i}^{a_{1}} \sigma^{a_{2}} v_{p}^{a_{3}} \mu^{a_{4}}$

By taking the natural logarithm of both sides of Eq. (5) gives

$\ln \delta_{\ell f}=\ln a_{0}+a_{1} \ln d_{i}+a_{2} \ln \sigma+a_{3} \ln v_{p}+a_{4} \ln \mu$

The constants may be found using a standard multi-linear regression technique. This technique was applied to a data set using distilled deaerated water as the working fluid, inside diameters 1.5 to $2.86 \mathrm{~mm}$, temperatures between 0 and $60{ }^{\circ} \mathrm{C}$, and hence with surface tensions of 0.0671 to $0.0786 \mathrm{~N} / \mathrm{m}$ and dynamic viscosities of 0.00049 to 0.00176 Pas, and average velocities of 0.33 to $1.8 \mathrm{~m} / \mathrm{s}$. The results of this analysis is given by way of Eq. 6 and to correlating coefficient $\mathrm{R}^{2}=$ $82 \%$ as

$\delta_{\ell f}=6031 d_{i}^{0.485} \sigma^{1.931} v_{p}{ }^{0.0942} \mu^{-0.130}$

where $\delta_{\ell f}$ is in $\mu \mathrm{m}$ if $d_{i}$ is in $\mu \mathrm{m}, \sigma$ is in $\mathrm{N} / \mathrm{m}, v$ is in $\mathrm{m} / \mathrm{s}$ and $\mu$ is in Pas. Fig. 4 shows the predicted values of the film thickness as a function of the experimentally determined values. It is seen that the predicted values tend to correspond to within about $\pm 15 \%$ of the experimentally determined values.

Table 1 Sensitivity analysis showing change in the predicted film thickness, using Eq. (7), for a $10 \%$ increase in a variable.

\begin{tabular}{|c|c|c|c|c|}
\hline Variable & $d$ & $\sigma$ & $v_{p}$ & $\mu$ \\
\hline Average value & 2.18 & 0.0726 & 1.07 & 0.00113 \\
& $\mathrm{~mm}$ & $\mathrm{~N} / \mathrm{m}$ & $\mathrm{m} / \mathrm{s}$ & $\mathrm{Pas}$ \\
\hline Original $\delta_{l f}$ & 135 & 135 & 135 & 135 \\
& $\mu \mathrm{m}$ & $\mu \mathrm{m}$ & $\mu \mathrm{m}$ & $\mu \mathrm{m}$ \\
\hline $10 \%$ increase & 0.218 & 0.00726 & 0.107 & 0.000113 \\
& $\mathrm{~mm}$ & $\mathrm{~N} / \mathrm{m}$ & $\mathrm{m} / \mathrm{s}$ & $\mathrm{Pas}$ \\
\hline New $\delta_{l f}$ & 141 & 162 & 136 & 133 \\
& $\mu \mathrm{m}$ & $\mu \mathrm{m}$ & $\mu \mathrm{m}$ & $\mu \mathrm{m}$ \\
\hline (New-old)/old & 4.73 & 20.20 & 0.90 & -1.23 \\
& $\%$ & $\%$ & $\%$ & $\%$ \\
\hline
\end{tabular}

An idea of the sensitivity of the correlating variables on the liquid film thickness can be obtained by systematically considering a $10 \%$ increase in the linear average of the upper and lower limits of each of the variables, in turn, keeping the other variable constant and taken as the average values of the upper and lower limits. Table 1 shows the percentage change in film thickness $\delta_{\ell f}$, using the correlation given by Eq. (7), for a $10 \%$ increase in the average value of each variable, keeping the other variables all constant. For example, for the average values given in the first row of Table 1 the correlation gives a film thickness $135 \mu \mathrm{m}$; if the surface tension $\sigma$ only is increased by $10 \%$ then the film thickness increases by $20.20 \%$ to $162 \mu \mathrm{m}$. The diameter, with a percentage difference between the new and old values of $4.73 \%$ is the next most significant variable, whilst the plug velocity and 
viscosity tend to show a more-or-less negligible effect on the film thickness.

\section{DISCUSSION and CONCLUSIONS}

In section 1 it was shown that there will always be a significant portion of the inside surface area that is covered by a thin layer of liquid, be it increasing in thickness in the condensing region or decreasing in the evaporating section. Further, should dry-out occur in the evaporator section it will not be for long before a passing liquid plug re-wets the surface. This is expected to be the case in both the vapour bubble-liquid plug model associated with the relatively low heat flux mode of operation as well as for the annular uni-directional model case associated with a high heat flux mode. As such, knowing the actual liquid film thickness is important in any attempt at theoretical modelling the performance of a pulsating heat pipe.

The correlation derived in section 4, based on the simple experiment experimental set-up and the procedure described in section 3 shows that the surface tension (see Table 1) is the dominant variable affecting the film thickness, the diameter is the next most important but viscosity and velocity appear to have a very small effect. This is interesting because for condensate thickness for film-wise condensation on a wall, other than for the heat transfer properties, the viscosity is important, albeit to a $1 / 4$ power (Mills, 1999). On reflection this is probable due to the small radius of curvature associated with film-wise condensation compared with the small radius of curvature of the liquidvapour interface in a small diameter tube where the surface tension is thus more important.

Further, from so-called film-theory the heat transfer coefficient may be given in terms of the thermal conductivity divided by the film thickness as $k / \delta \approx 0.65 / 0.0001=6500 \mathrm{~W} / \mathrm{m}^{2} \cdot{ }^{\circ} \mathrm{C}$, which from an overall heat transfer point of view may not appear important if the outside heat transfer coefficient is much smaller, thereby dwarfing the effect of the inside heat transfer coefficient on the overall heat transfer rate. Nonetheless, this argument does not lessen the effect of the inside heat transfer coefficient on the rate at which the film is increasing or decreasing (and even drying out). The rate at which the inside film thickness changes is indicative of the rate at which the vapour pressure changes and consequently the rate and intensity at which the pulsations occur in the PHP.

Water was used in this study, because it is so easy to use from an experimental point of view. The correlation given by Eq. (7) predicts average thicknesses of the liquid film deposited on the wall by the trailing end of a liquid plug of between 100 and $200 \mu \mathrm{m}$, for water temperatures of between 0 and $60{ }^{\circ} \mathrm{C}$ (and hence surface tensions of between 0.0671 and $0.0786 \mathrm{~N} / \mathrm{m}$ and dynamic viscosities of between 0.00049 and 0.00176 Pas) and liquid plug velocities of 0.33 to $1.8 \mathrm{~m} / \mathrm{s}$. Equation (7) can be used for water with reasonable confidence within these limits. It may however not necessarily be as accurate for other working fluids; this still needs to be fully investigated and tested. Nevertheless the given correlation can be used to evaluate the theoretical accuracy/validity of a mathematical simulation model.

\section{ACKNOWLEDGEMENTS}

This work was partially funded by a grant from CAE (Pty) LTD, Atlantis, South Africa.

\section{NOMENCLATURE}

$d \quad$ diameter $(\mathrm{m})$

$k \quad$ themal conductivity $\left(\mathrm{W} / \mathrm{m} \cdot{ }^{\circ} \mathrm{C}\right)$

L length (m)

$m$ mass $(\mathrm{kg})$

$\begin{array}{ll}\mathrm{g} & \text { gravitational constant } \mathrm{m} / \mathrm{s}^{2} \\ \mathrm{R}^{2} & \text { coefficient of determination } \\ t & \text { time (s) }\end{array}$

$v \quad$ velocity $(\mathrm{m} / \mathrm{s})$

Greek Symbols

$\delta \quad$ film-thickness (m)

$\rho \quad$ density $\left(\mathrm{kg} / \mathrm{m}^{3}\right)$

$\sigma \quad$ surface tension (N/m)

$\mu \quad$ dynamic viscosity (Pas)

Subscripts

$f \quad$ liquid-film

$i \quad$ initial condition

$\ell \quad$ liquid

min minimum

$p \quad$ liquid-plug

$t$ tube

$v \quad$ vapour

\section{REFERENCES}

Akachi, H., 1990, Structure of a Heat Pipe, U.S. Patent \#4,921,041.

Akachi, H., 1993, Structure of Micro-Heat Pipe, U.S. Patent $\# 5,219,020$.

Akachi H., Polášek F., 1996, Pulsating heat pipes, Proceedings of the 5th International Heat Pipe Symposium, Melbourne, Australia, 17-20 November.

Carey, V.P., 1992, Liquid-Vapor Phase Change Phenomena, Hemisphere.

Charoensawan, P., Khandekar, S., Groll, M., Terdtoon, P., 2003, Closed loop pulsating heat pipes: Parts A and B, Applied Thermal Engineering, Volume 23, Issue 16, November, Pages 2009-2020 and 2021-2033.

Dobson, R. T. and Harms, T. M., 1999, Lumped parameter analysis of closed and open oscillatory heat pipes. Proceedings of the 11th International heat pipe Conference, Tokyo, 12-16 Sept.

Dobson, R. T., 2002, Theoretical and experimental modelling of an open oscillatory heat pipe including gravity, Proceedings of the 12th International Heat Pipe Conference, Moscow-Kostroma-Moscow, May $19-24$.

Dobson, R. T., 2003, An open oscillatory heat pipe steam powered boat, International Journal Mechanical Engineering Education, Volume 31, Number 4, October.

Dobson, R. T., Graf, G., 2003, Thermal characterisation of an ammoniacharged pulsating heat pipe, Proceedings of the 7th International Heat Pipe Symposium, Jeju, Korea, October 12-16.

Khandekar, S. and Groll, M., 2008, Roadmap to realistic modelling of closed loop pulsating heat pipes, Proceedings of the 9th International Heat Pipe Symposium, November 17-20, Selangor, (Kuala Lumpur), Malaysia.

Intagun, W., Sakulchangsatai, P., Tertoon, P., Effect of working fluids on internal flow patterns of closed-loop oscillating heat pipe at maximum heat flux state, Proceedings of the 9th International Heat 
Pipe Symposium, November 17-20, Selangor, (Kuala Lumpur), Malaysia.

Mills, A. F., 1999, Heat Transfer, Prentice Hall.

Polášek F., Zelko M., 1997, Thermal control of electronic components by heat pipes and thermosyphons; a historical overview, Proceedings of the 10th International Heat Pipe Conference, Stuttgart, Germany, 21-25 September.

Senjaya, R., Inoue, T., Suzuki, Y., 2010, Oscillating heat pipe simulation with bubble generation, Proceedings of the 15th International Heat Pipe Conference (15th IHPC), Clemson, USA, April 25-30.

Shafii M.B., Faghri A., Zhang Y., 2001, Thermal modelling of unlooped and looped pulsating heat pipes, Journal of Heat Transfer, Volume 123, pp 1159-1172.

$\underline{\text { doi: } 10.1115 / 1.1409266}$

Shao, W., Zhang, Y., 2010, Effects of capillarity and gravitational forces on oscillatory flow and heat transfer in an oscillating heat pipe,
Proceedings of the 15th International Heat Pipe Conference $\left(15^{\text {th }}\right.$ IHPC), Clemson, USA, April 25-30.

Swanepoel, G., Taylor, A. B. and Dobson, R. T., 2000, Theoretical modelling of pulsating heat pipes, Proceedings of the $6^{\text {th }}$ International Heat Pipe Symposium, Chiang Mai, Thailand, 5-9 November 2000.

Tripathi, A., Khandekar, S., Panigrahi, P. K., 2010, Oscillatory contact line motion inside capillaries, Proceedings of the 15th International Heat Pipe Conference (15th IHPC), Clemson, USA, April 25-30.

Wong T.N., et al., Theoretical modelling of pulsating heat pipe, Proceedings of the 11th International Heat Pipe Conference, Tokyo, 12-16 September 1999.

Zhang, Y., Faghri, A. 2002, Heat transfer in a pulsating heat pipe with open end, International Journal of Heat and Mass Transfer, Volume 45, Issue 4, February, Pages 755-764. doi:10.1016/S0017-9310(01)00203-4. 